\title{
Commentary on "CTLA-4 Blockade Suppresses Progression of Residual Tumours after Insufficient RFA"
}

\author{
B. Geboers ${ }^{1}$ (I) M. R. Meijerink ${ }^{1}$
}

Received: 4 June 2020/ Accepted: 17 June 2020/Published online: 24 July 2020

(C) The Author(s) 2020

\section{Introduction}

Image-guided tumour ablation has developed into a wellestablished treatment paradigm for solid cancers. As reflected by the increasing number of key publications in CVIR, several needle-guided thermal and non-thermal ablation techniques have evolved into reliable and widely adopted therapies in modern clinical oncology. Although complete tumour eradication has always been the primary objective, fundamental changes to this basic concept may be in the offing. Anecdotal reports of spontaneous regression of distant tumours following local tumour ablation (i.e. abscopal effect) triggered research of the underlying systemic immune mechanisms. This effort is gradually evolving into novel treatment approaches where focal tumour ablation is combined with passive or active immunotherapy.

Immunomodulating properties have been identified for all energy-based needle-guided ablative modalities [1]. Evidence that local ablation may lead to systemic tumour control through the priming and boosting of tumourspecific adaptive immunity, in effect resulting in in vivo vaccination, is found in several tumour types [2]. Conversely, clinical evidence for ablation-induced counteractive pro-oncogenic effects similarly exists and has been linked to aggressive tumour development and worse outcomes [3].

\section{R. Meijerink}

mr.meijerink@amsterdamumc.nl

1 Department of Radiology and Nuclear Medicine, Amsterdam University Medical Centers (location VUmc), de Boelelaan 1117, 1081 HV Amsterdam, The Netherlands
Local tumour progression (LTP) due to an incomplete ablation remains a major drawback of needle-guided tumour ablation. In this issue of CVIR, we are treated to an article by Zhang et al. [4] who were the first to investigate administration of CTLA-4 blockade after an 'insufficient' radiofrequency ablation (RFA) as potential solution for the development of LTP. The authors report the tumour response, histopathology, and survival of 40 mice with subcutaneously implanted HCCs treated with either (1) IgG control antibody, (2) insufficient RFA, (3) CTLA-4 blockade, or (4) insufficient RFA followed by CTLA-4 blockade. Only mice in the combination therapy group survived the follow-up period of 48 days (5 out of 8 ) and 3 out of 8 mice showed completely vanished residual tumours, while none in the other groups responded. Addition of anti-CTLA-4 to insufficient RFA significantly improved survival and suppressed residual tumour growth. Combined with the histopathological observation of significantly increased CD4 $+\mathrm{T}$ cell infiltration and IFN-Y concentrations, these results are indicative for the establishment of an effective adaptive systemic immune reaction. Tumour re-challenging confirmed that the augmentation of anti-tumour immunity has potential to become durable as 2 out of the 5 surviving mice showed complete tumour rejection.

However, some degree of reservation towards the results is required as the follow-up time was short, side effects of the combination therapy were not reported and, foremost, because animal results can be far-off translation into clinical practice. Furthermore, 2 of the surviving mice developed rapid and massive tumour growth after tumour rechallenging suggestive for latent pro-oncogenic effects. 
In conclusion, this study supports the rationale to combine thermal ablation with checkpoint inhibition for HCCs. This proof of concept now warrants further investigation of the optimal dosage, timing, and sequencing of both therapies taking into account potential pro-oncogenic effects. If results can be clinically reproduced, the combination regimen may not only provide an alternative strategy to prevent LTP after HCC ablation, even a paradigm shift towards intentional incomplete ablations combined with immune enhancing drugs is conceivable. Interventional oncologists are well positioned in the centre of oncological care and, given the rise of immunotherapy, the integration of immuno-oncology in interventional oncology is inevitable, as stated in the Society of Interventional Oncology White Paper on the emerging role of immunotherapy in interventional oncology [5]. Considering their expanding role interventionists should guide this exciting revolution while acknowledging close collaborations with immuneoncologists and medical oncologists. If smart combinations with focal therapy truly prove to trigger systemic anti-tumour effects and excite durable responses, focal ablation may eventually provide the bridge between local and systemic treatment.

Funding This study was not supported by any funding.

\section{Compliance with Ethical Standards}

Conflict of interest The authors declare that they have no conflict of interest.

Consent for publication For this type of study, consent for publication is not required.

Ethical approval This article does not contain any studies with human participants or animals performed by any of the authors.
Informed consent For this type of study, informed consent is not required.

Open Access This article is licensed under a Creative Commons Attribution 4.0 International License, which permits use, sharing, adaptation, distribution and reproduction in any medium or format, as long as you give appropriate credit to the original author(s) and the source, provide a link to the Creative Commons licence, and indicate if changes were made. The images or other third party material in this article are included in the article's Creative Commons licence, unless indicated otherwise in a credit line to the material. If material is not included in the article's Creative Commons licence and your intended use is not permitted by statutory regulation or exceeds the permitted use, you will need to obtain permission directly from the copyright holder. To view a copy of this licence, visit http://creativecommons. org/licenses/by/4.0/.

\section{References}

1. Shao Q, O'Flanagan S, Lam T, Roy P, Pelaez F, Burbach BJ, et al. Engineering $\mathrm{T}$ cell response to cancer antigens by choice of focal therapeutic conditions. Int J Hyperth Off J Eur Soc Hyperth Oncol N Am Hyperth Group. 2019;36(1):130-8.

2. Geboers B, Ruarus AH, Nieuwenhuizen S, Puijk RS, Scheffer HJ, de Gruijl TD, et al. Needle-guided ablation of locally advanced pancreatic cancer: cytoreduction or immunomodulation by in vivo vaccination? Chin Clin Oncol. 2019;8(6):61.

3. Kang TW, Kim JM, Rhim H, Lee MW, Kim YS, Lim HK, et al. Small hepatocellular carcinoma: radiofrequency ablation versus nonanatomic resection-propensity score analyses of long-term outcomes. Radiology. 2015;275(3):908-19.

4. Zhang L, Wang J, Jiang J, Zhang M, Shen J. CTLA-4 blockade suppresses progression of residual tumors and improves survival after insufficient radiofrequency ablation in a subcutaneous murine hepatocellular carcinoma model. Cardiovasc Int Radiol. 2020. https://doi.org/10.1007/s00270-020-02505-6.

5. Erinjeri JP, Fine GC, Adema GJ, Ahmed M, Chapiro J, den Brok $\mathrm{M}$, et al. Immunotherapy and the interventional oncologist: challenges and opportunities-a society of interventional oncology white paper. Radiology. 2019;292(1):25-34.

Publisher's Note Springer Nature remains neutral with regard to jurisdictional claims in published maps and institutional affiliations. 